\author{
Пятова О.Ф. \\ ФГБОУ ВО Самарская ГСХА \\ Кинель, Россия
}

doi: 10.18411/lj2016-3-94

\title{
Оценка динамики материального положения сельских домохозяйств Самарской области
}

Несмотря на определенные позитивные подвижки, произошедшие за несколько последних лет, сложившаяся в социально-трудовой сфере российского села ситуация характеризуется комплексом накопившихся проблем, препятствующих более полному и эффективному использованию природного, материально-технического и трудового потенциала сельских территорий, выполнению селом его общенациональных функций.

Реализация «Программы развития села до 2013 года» предусматривала софинансирование программных мероприятий за счет средств федерального бюджета, консолидированных бюджетов субъектов Российской Федерации и внебюджетных источников [1].

На выполнение программных мероприятий из федерального бюджета было выделено 48,4 млрд. руб. Государственная поддержка из федерального бюджета стимулировала привлечение средств консолидированных бюджетов субъектов Российской Федерации в объеме 104,7 млрд. руб. и средств внебюджетных источников в объеме 113,1 млрд. руб.

Таким образом, на каждый рубль средств федерального бюджета, выделенный на реализацию Программы развития села до 2013 года, привлечено 4,5 рубля средств бюджетов субъектов Российской Федерации и внебюджетных источников [1]. 
В Самарской области общий объем средств областного бюджета формируется с учетом поступающих в областной бюджет средств федерального бюджета (в соответствии с действующим законодательством) с разбивкой по годам действия программы. Он составляет 4632,75 млн. руб., в том числе из федерального бюджета 1664,25 млн. руб.[2].

Цель данного исследования - выявление связи изменения состояния социально-трудовой сферы села с реализацией ФЦП «Социальное развитие села до 2013 года» и ФЦП «Устойчивое развитие сельских территорий на 2014-2017 годы и на период до 2020 года».

Для достижения поставленной цели необходимо решить следующие задачи:

- выявить субъективную интерпретацию протекающих в сельской местности социально-экономических процессов,

- дать оценку изменениям в условиях жизни, материального положения домохозяйств.

Рассчитанный автором коэффициент сводной оценки ситуации социальнотрудовой сферы за период 2011-2013 гг. свидетельствует об улучшении ситуации в Самарской области. Следует охарактеризовать изменение ситуации в сельской местности [3].

В работе представлены материалы опросов, проводимых в 2012-2014 годах, где респонденты оценивали ситуацию 2011-2013 годов соответственно. При проведении исследования в опросе приняли участие сельские жители, проживающие в селах и поселениях муниципальных районов, относящихся к разным природно-экономическим зонам. В 2012 г. опросом охвачено 250 домохозяйств, в 2013 г. - 247, в 2014 г. - 277.

Предстояло выяснить, как оценивают сами жители происходящие изменения.

В 2013 г. большинство респондентов посчитало, что материальное положение осталось без изменений по сравнению с предыдущим периодом. 
Доля их составила 64,5\%. Среди женщин такое мнение высказали 68,9\%. Анализ изменения материального положения сельских домохозяйств выявил устойчивую тенденцию снижения доли лиц, считающих, что ситуация ухудшается. Тех, кто затруднился с определением материального положения своего домохозяйства, стало намного меньше.

Один из вопросов, на которые предстояло ответить респондентам, содержал оценку состояния материального положения своего домохозяйства. Предлагалось несколько ответов на вопрос (таблица 1).

\begin{tabular}{|c|c|c|c|c|c|c|c|c|c|c|c|}
\hline \multirow{3}{*}{$\begin{array}{l}\text { Возрастные } \\
\text { группы } \\
\text { респондентов }\end{array}$} & \multicolumn{10}{|c|}{ Мы живем } & \multirow{3}{*}{ итого } \\
\hline & \multicolumn{2}{|c|}{ богато } & \multicolumn{2}{|c|}{$\begin{array}{l}\text { в } \\
\text { достатке }\end{array}$} & \multicolumn{2}{|c|}{$\begin{array}{l}\text { бедно, едва } \\
\text { сводим } \\
\text { концы с } \\
\text { концами }\end{array}$} & \multicolumn{2}{|c|}{$\begin{array}{l}\text { очень } \\
\text { бедно }\end{array}$} & \multicolumn{2}{|c|}{$\begin{array}{l}\text { затрудняюсь } \\
\text { с ответом }\end{array}$} & \\
\hline & $\stackrel{\dot{\leftrightarrow}}{\stackrel{\sim}{\sigma}}$ & $\stackrel{\dot{m}}{\dot{0}}$ & 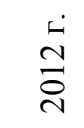 & $\stackrel{\dot{m}}{\stackrel{m}{\sigma}}$ & $\stackrel{\dot{\sim}}{\stackrel{0}{O}}$ & $\stackrel{\dot{m}}{\stackrel{\dot{n}}{\sigma}}$ & 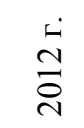 & 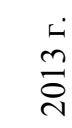 & $\frac{\dot{\sim}}{\stackrel{2}{O}}$ & $\frac{\dot{m}}{\dot{n}}$ & \\
\hline $18-30$ & 4,3 & - & 69,6 & 69,6 & 11,6 & 13,0 & 1,4 & - & 13,0 & 17,4 & 100 \\
\hline $31-40$ & 2,4 & - & 44,6 & 36,8 & 25,3 & 52,6 & 7,2 & - & 20,5 & 10,5 & 100 \\
\hline $41-54(59)$ & 1,3 & - & 52,7 & 50,7 & 23,0 & 23,9 & 4,1 & - & 18,9 & 25,4 & 100 \\
\hline св. 54 (59) & - & - & 35,0 & 64,7 & 50,0 & 29,4 & 10,0 & - & 5,0 & 5,9 & 100 \\
\hline итого & 2,4 & - & 53,3 & 53,9 & 22,8 & 26,9 & 4,9 & - & 16,7 & 19,2 & 100 \\
\hline
\end{tabular}

По результатам опроса о ситуации большинство респондентов всех возрастных групп ответили, что живут в достатке. Такие ответы присутствует и у респондентов-мужчин, и респондентов-женщин.

Если в 2012 г. небольшая часть опрошенных сельчан считала, что живет богато, то в 2013 г. ни один респондент не выбрал этот ответ.

Увеличилась доля лиц, считающих, что «едва сводят концы с концами».

Одним из наиболее интересных вопросов, на который респондентам предстояло ответить, заключался в оценке соответствия материального положения семьи тому, что они заслуживают. Варианты ответов предлагались следующие:

- - материальное положение лучше того, что мы заслуживаем;

- - имеем то, что заслуживаем;

- - наше положение хуже того, что мы заслуживаем; 
- - затрудняюсь с ответом.

Обработка ответов дала такие результаты (таблица 2).

Таблииа 2 - Самооиенка соответствия материального положения тому, что заслуживает домохозяйство в

\begin{tabular}{|l|l|l|l|}
\hline Варианты ответов $2011-2013$ г2., \% & 2013 г. \\
\hline Материальное положение лучше того, что мы заслуживаем & 2011 г. & 2012 г. & 2013,8 \\
\hline Имеем то, что заслуживаем & 0,4 & 3,3 & 0,8 \\
\hline Наше положение хуже того, что мы заслуживаем & 34,4 & 47,2 & 46,2 \\
\hline Затрудняюсь с ответом & 56,8 & 39,0 & 43,8 \\
\hline
\end{tabular}

Снижается доля тех, кто считает, что их положении недооценено - с с 56.8\% до 46,2\%. Увеличивается доля респондентов, которые критично смотрят на положение своего домохозяйства.

Только в 2013 г. по оценке за прошедший год (2012 г.) были ответы о лучшем положении семьи. В основном респонденты придерживались того мнения, что имеют то, что заслужили. Таких респондентов больше среди мужчин.

Кроме этих вопросов, респондентам было предложено оценить изменение материального положения в будущем. Предложено 4 вариантов ответа:

- -надеюсь, улучшится;

- - скорее всего, останется без изменений;

- - думаю, ухудшится;

- - затрудняюсь с ответом.

Ответы на вопрос о прогнозе материального положения отражают экономическое настроение респондентов, потребительскую и социальную уверенность в близкой перспективе. Обычно респонденты строят прогнозы материального положения на основании нескольких факторов: собственное ощущение макросреды, виденье карьерных перспектив, прогнозирование доходов от капитала и т.п. На этот вопрос были получены следующие ответы (рисунок 1).

Наблюдается положительный тренд, т.е. увеличивается доля лиц, считающих, что их положение улучшится и снижается доля тех, кто с пессимизмом смотрит в будущее. Таких лиц больше среди мужчин. 
Около $40 \%$ участников проведенного исследования видят свое материальное положение в следующем году с осторожным оптимизмом, предполагая, что оно может остаться неизменным.

Чем старше респондент, тем более пессимистичен его прогноз относительно изменений в материальном положении домохозяйств.

Принявшие участи в опросе в 2014 году респонденты старшей возрастной группы, тем не менее, в большинстве своем надеются на стабилизацию ситуации в домохозяйствах.

Политическое руководство страны, представители агропромышленного сектора экономики остро ставят вопрос об обеспечении продовольственной безопасности государства как одну из приоритетных задач. Обеспечение российского потребительского рынка конкурентоспособной сельхозпродукцией и продовольствием отечественного производства невозможно без устойчивого развития сельских территорий.

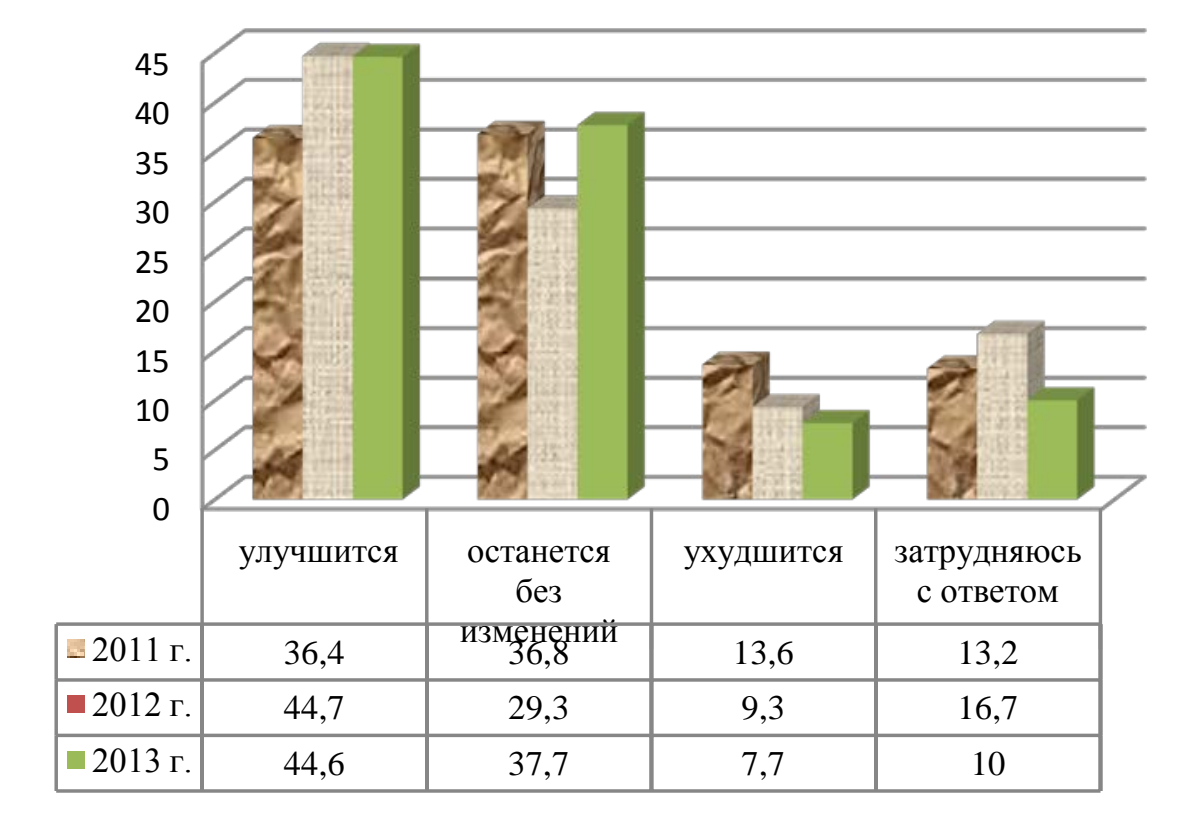

Рисунок 1 - Прогноз изменения материального положения домохозяйств в 2011-2013 гг., в \% от общего числа респондентов

Социально-экономическая политика в отношении сельских территорий должна основываться на комплексном анализе демографической ситуации, производственного потенциала, социальной структуры и других факторов с учетом их потенциального изменения. 


\section{Литература:}

1. $\quad$ О предварительных итогах реализации Программы развития села до 2013 года// [Электронный pecypc]: URL: http://www.garant.ru/products/ipo/prime/doc/70155950 (дата обращения 25.12.2014 г.).

2. О социальном развитии села в Самарской области./ [Электронный pecypc]: URL: /http://www.mcx.ru/news/news/show/8781.htm

3. Пятова, О.Ф. Сводная оценка ситуации социально-трудовой сферы Самарской области// Известия Самар. гос. с.-х. акад. - 2015.-№2. - С. 3-6. 